\title{
Teachers' Awareness, Attitude and Practice of Teaching Primary School Science Curriculum Vis-A-Vis Constructivist Approach
}

\author{
Ayele Lemma (Mr.) \\ Robe College of Teachers Education, Education Stream, \\ Department of Curriculum and Instruction, Bale-Robe, Ethiopia
}

\begin{abstract}
The purpose of this study was to investigate teachers' awareness, attitude and practice of teaching primary school science curriculum towards constructivist approach. The study was to see how teachers teach the primary science curriculum at classroom level vis-à-vis constructivist approach, as well as, to identify teachers' awareness and attitude toward constructivist view of teaching and learning in science education. The sources of the data were selected purposefully from science teachers, who teach from grade one to grade six, of one purposefully selected primary school. Qualitative research paradigm and case study research design were used as the methods of the study. The data was analyzed qualitatively. The result revealed that: 1) Teachers were using the traditional approach, lecture as pivotal tool in their classroom episodes; 2) Teachers did not have the understanding of constructivist approach in-depth. Teachers perceived as their direct teaching/purveying of scientific findings could develop the understanding of scientific concepts and skills; 3) Teachers' attitude towards students' motivation and capabilities in their learning with respect to constructivist view of learning reflected more of pessimistic views. This attitude is the result of the deep rooted thoughts of positivist/objectivist view and lack of awareness towards constructivist view of learning. Finally, the following solutions were recommended for the identified problems as:1) The Regional Education Bureau, the Zonal Education Office and the Town administration Education Office ought to provide workshops, short term trainings on constructivist approach as referent thinking in science education. 2) The Schools' Administrators also need to arrange experience sharing among science teachers on content pedagogy in line to constructive view of learning. 3) Teachers educators ought to develop the understanding of the would-be teachers towards constructivist approach.
\end{abstract}

Keywords: Constructivist approach, Awareness, Attitude and Practice

DOI: $10.7176 / \mathrm{JEP} / 12-13-06$

Publication date:May $31^{\text {st }} 2021$

\section{INTRODUCTION}

Background of the Study

The underlying principle of constructivist teaching/instruction comes from an epistemological difference between the objectivist/positivist and the constructivist epistemology of knowledge. To the objectivist epistemology, knowledge is believed to exist independently of the learner, and then to become internalized as it is transferred from the mind of the teacher/external sources to the mind of the learner, seeing that it is infused directly (Littledyke, 2001; Mayer, 2003; Hillocks, 1999). In other words, knowledge is independent of a thinking being and can be mapped onto a learner.

Positivist/objectivist assumptions about education can result in mechanistic/transmission approach to teaching and learning which commonly produce rote learning without meaningful learning or understanding (Littledyke, 2001; Rose and Billett, 1999; Mayer, 2003; Petty, 2004; Hillocks, 1999). In line to this, teaching is viewed as:

Teaching is tantamount to telling. This telling may take place through a text book, a lecture, recitation, or visual demonstrations. The assumption is that, if one tells or gives students appropriate information, their learning will indicate that they have received the information and made use of it (Hillocks, 1999:19).

Such a model has epistemological implications, namely that knowledge is objective, and may be acquired through words and senses. The traditional, objectivist epistemology is the underpinning assumption of teachercentered teaching methods (Hillocks, 1999; Mayer, 2003; Littledyke, 2001). In the traditional teaching methods, the teachers' job is "giving out" or to transfer knowledge to the students directly. The learner is a recipient of information, whose job is to accept, manipulate, store and retrieve information (Rose and Billett, 1999; Mayer, 2003; Petty, 2004; Cottrel, 2001; Kumari and Sharma, 2004).

According to this view, there is a belief that knowledge could be transfused intact into the mind of one another. That is knowledge could be conveyed directly through words or via information delivering methods/expositors and could be apprehended directly by anyone having adequate facility in the language (Hillocks, 1999; Mayer, 2003; Littledyke, 2001).

The influences of positivist/objectivist views in education have the effect of inculcating children with information/knowledge of prescribed truths; without enabling them to think in action and reflect on its significance. 
It considers the mind of the child as "tabula rasa" on which the function of education is to inscribe the truth of the features of the world (Mayer, 2003; Rose and Billett, 1999; Ross, 200; Black, 1999).

Consequently, the early path of science instruction followed the view of exercising student's minds through rote memorization of information. According to Kumari (2004); Garson (2002); NSRC (1999), traditionally the primary method to teach science was having students to read text books and listen to lectures in which major scientific findings were described as facts and the particulars of scientific methods and procedures were often minimized or omitted entirely.

However, the field of education has undergone a significant shift in thinking about the nature of human learning and the condition that best promote the varied dimension of human learning. There has been a paradigm shift in instructional design; from objectivist tradition- behaviorism and cognitivism (Mayer, 2003; Hillock, 1999) to constructivist approach in which knowledge is a function of how the individual create meaning from his or her own experience.

According to the constructivist, in contrast to the objectivist view, knowledge is being actively constructed by the individual and knowing is an adaptive process, which organizes the individual's experiential world (littldyke, 2001; Mayer, 2003 ). Hence, the learner is not considered as passive recipients but as 'already a scientist' (Bruner, 1966 in Kumari, 2004) who actively constructs knowing while striving to make sense of the world on the basis of personal filters: experiences, goals, curiosities and beliefs (Hillocks, 1999; Littledyke, 2001).

Thus, constructivist approach has been advocated for science education currently; for the science curriculum to reflect a constructivist epistemology and for a paradigm shift to constructivist pedagogy. Hence, constructivist instruction will help the young child to develop meaningful knowledge of the concept of science, skills in methods of science/process skills and enthusiasm for scientific inquiry (NSCR, 1997; McGuigan and Shilling 1997; Byrne, 1997; Kumari and Sharma, 2004).

Accordingly, the instructional strategies that are suggested by educators and cognitive scientists for the application of constructivist approach, which teachers need to adapt, are classified into five series of phases (Littledyke, 2001:13-21; Brice, 2001:89; Ross, 2001:71; NSRC, 1997:26).

These are

\section{Orientation}

using children's interest, curiosity and motivation

- Arousing child

- Helping children to describe, find out, and clarify their conceptions, what they think, feel about the topic

3. Intervention/Exploration

- Encouraging children to test their prior conception, ideas, feeling to extend, develop or modify them.

4. Reflect/Review

- Helping children to recognize the significance of what they have found out or what have been achieved and communicate, argue their ideas.

\section{Application/Connect}

- Helping children to relate what they have learned or achieved to their everyday lives or meaningful activity.

Similarly, Transitional Government of Ethiopia (TGE) (1994) advocates a paradigm shift in teaching and learning process. That is, it recommends a shift of instructional methods from teacher-centered approach to student- centered approach in education. In short, TGE (1994) promotes interpretive pedagogy which is constructivist approach (Yalew, 2004).

Thus, for the implementation of constructivist approach teachers' knowledge, skills and attitudes toward constructivism have a crucial role. In other words, teachers' constructivist conception of learning and beliefs towards students' capabilities to learn on their own determine the way of their instructional practices (Hillock, 1999; Kumari and Sharma, 2004; Littledyke, 2001; Ross, 2001; NSCR, 1999). Accordingly, the objective of this paper was to investigate teachers' awareness, attitude and practices of teaching science education toward constructivist approach in primary school.

\section{Statement of the Problem}

Teachers' conception of how students achieve understanding, will influence their decision about the ways in which they organize their classrooms, their choice of strategies or activities, and their interaction with their students. This implies for the effective implementation of constructivist approach, teachers' awareness, skills and attitudes towards constructivist view of teaching and learning have indispensable role. It requires a constructivist conception of learning: namely, that what is learned may only be learned in terms of what we already know and the learner must construct what is to be learned for themselves (Kumari and Sharma, 2004; Littledyke, 2001; Hillocks, 1999). 
If the teachers have awareness and optimistic attitude towards constructivist learning, then they could approach their instructional processes by giving emphasize to constructivists approach. Teachers who emphasize the constructivist view of learning assist their students to participate actively in making their own knowledge out of the materials presented to them. Teachers with these optimistic attitudes assume that students themselves construct meaning in the learning process when they are supported. Hence, students require opportunity to experience what they are to learn in a direct way and understand by modifying their preexisting ideas in the light of the new insights gained from their performance of active involvement (Kumari and Sharma, 2004; Littledyke, 2001).

Accordingly, as Lambert and McCombs (1998:10) quoted in Yalew (2004:19) stated,

Learning is constructive process that occurs best when what is being learned is relevant and meaningful to the learner and when the learner is actively engaged in creating his or her own knowledge and understanding by connecting what is being learned with prior knowledge and experience

Therefore, the constructivist approach enables the students to learn by directly experiencing learning activities to develop meaningful knowledge via exchanging ideas of their views and working together to verify with scientific thinking/concepts, and arguing their interpretations.

On the other hand, teachers with non-optimist attitude towards constructivist learning belief that student learn best if teachers present lessons and consider themselves the major source of knowledge to the students. These teachers' belief about teaching assumed that teaching is the process of transmitting information from the teacher to the learners. They dominate the class, talk much of the regular class time, and give little chance to the students to interact in the class discussions (Kumari and Sharma, 2004; Yalew ,2004; Hillocks, 1999).

Conversely, when teaching is viewed from antiquated line of imparting knowledge children do not acquire meaningful knowledge /understanding, skills and attitudes. This assumption of teaching results learning which commonly produce rote learning, learning without meaningful knowledge. Understanding and competence come through the children's active engagement with learning experiences. Unless students are encouraged to actively participate and derive meaning from their interaction with their environment, their motivation to learn could decrease and the quality of science education, which is expressed mainly through students' achievements, deteriorates (Yalew,2004; Mayer,2003).

Similarly, McGuigan and Shilling (1997:30) argued the drawbacks of objectivist view of instruction as follows:

The direct transmission of science knowledge by the teacher to students assuming that there is a direct correspondence between that which is delivered by the teacher and that which is received by child would neglect not only the range of ideas within a class but also fail to take account of the constructivist view of how children make progress in their own understanding.

Thus, to attain the basic science objectives, such as, developing conceptual understanding, strengthening process skills, cultivating attitude toward science and to make learning meaningful to children, instructional activities that could facilitate constructivist approach need to be used. Hence, the constructivist pedagogy enables the students to learn: with understanding of scientific facts and concepts, to use/apply their understandings to new situations, develop process skills/ science procedural knowledge, and develop attitudes such as willing to tolerate uncertainty, to co-operate with others, to give honest reports and to think critically.

Thus, to equip the pupils with desirable objectives of science education teachers ought to have understanding and optimistic attitude towards constructivist view of learning. In line to this, I couldn't come-across similar works/researches that could reveal teachers' awareness, attitude and practices vis-a-vis constructivist approach in teaching primary science education, in our context as far as my access to literature is concerned. Thus, this gap made me to carrying out this investigation.

\section{Objectives of the study}

Thus, this research was intended to:

1. To describe teachers' current classroom episodes in teaching primary science curriculum vis-a-vis constructivist approach.

2. To identify teachers' awareness toward constructivist approach.

3. To find out teachers' attitude towards students' learning constructively.

\section{Method and Design of the Research Research Method}

Qualitative research method was used in this research, because of the fact that the qualitative research tradition could help to study the human perceptions, values, attitudes, experience \& activities in natural setting (Ary et.al., 2002). Moreover, qualitative approach permits the researchers to focus on participants' perception and experiences and can understand how things occur. Hence, qualitative research paradigm is an inquiry process of understanding 
a phenomenon by focusing on the total picture, rather than breaking it down in to variables. The goal is holistic picture and depth understanding rather than numeric analysis of data (Ary et.al., 2002; Solomon, 2004). In other words, it seeks to understand social and human practices and problem from the insider's perspective through looking closely at words, actions and records. More specifically, case study design was used. It is one of the strategies in qualitative methodology in which the researchers explore in- depth a program, an event, an activity and a process in natural settings. In relation to this, Solomon (2004) states, a case study is a preferred strategy when the emphasis is on understanding of why the individual does, what he/she does and how behavior changes as individual respond to the environment. In other words, a qualitative case study has focused on a few cases in a considerable depth. Yin (2003) also noted that qualitative case study has focused on a few cases and variables, that take few research settings to makes detail explanations around and in the research setting. This research, therefore considered one purposefully selected research setting.

\section{Sampling Techniques}

Purposive/non-probability method of sampling was used in this study. Accordingly, the research setting is selected purposefully depend on the accessibility in terms of distance and time taken from my work place. Since, qualitative paradigm demands that the researcher to stay in the setting over the time (Amare, 2004; Kumar, 1996; Ary, et.al. 2002).

Likewise, the sources of the data were selected purposefully from teachers who teach Environmental science (grade 1-4), which were 4 in number and from teachers who teach Integrated science (grade 5-6), which were 3 in number. These respondents, who could provide relevant information about the topic, were selected "purposively to exploit competing views and fresh perspectives as fully as possible" (Lincoln and Guba, 1981:276 in Ary, et.al. 2002). Accordingly, after through discussion was made with school director and with themselves (these teachers), two teachers were excluded and the remained five teachers involved in the study.

The study was confined to these teachers to make the study manageable, since the study requires frequent/continuous classroom observation and recordings. Besides, an in-depth interview, which requires a great deal of time, was made with the subjects/respondents. The name of the participants and the school/the site represented by pseudo/fictitious names to protect their privacy (Ary, et. al. 2002:471).

\section{Data Collection Techniques}

The most common data collection methods used in qualitative research are observation, recording/field notes, interviewing and document analysis (Ary, et al. 2002). Accordingly, for this study observation, field notes and interviews were used.

Observation: In the process of observation all of behaviors and characters which exhibited by teachers and students in the classroom were recorded. The selected teachers were observed at least twice in the classroom when they teach a lesson. Through the observation session classroom episodes were tried to recorded as much as possible focusing on following two focal areas:

1. Teachers' practice in approaching subject matter/content vis-à-vis constructivist approach

- Teachers' effort in arousing students' curiosity and motivation

- Teachers' effort in helping the students to describe their prior conceptions or experiences

- Teachers' effort in helping the students to test their prior conceptions

- Teachers' attempt in facilitating condition for reflection and meaning sharing

2. Students involvement in learning process

- The nature of students' participation in the learning process

- Students' involvement in expressing their prior experiences/conceptions

- Students' active engagement in testing their ideas

- Students' involvement in reflection and sharing their interpretations

Interviews: are used to gather data on subjects' understanding, opinions, beliefs, and feeling about the topic in their own words (Amare, 2004; Ary, et.al. 2002). "Subjects are free to answer in their own words rather than having to choose from predetermined option as in a survey" (Ary, et.al. 2002:27). Less/semi-structured interviews were used in this research to explore the underlying assumptions of teachers' current practices.

Accordingly, the selected teachers were interviewed to obtain valuable information about their understanding, and attitude towards constructivist learning in science education. It is used to verify the observation. The interview data were recorded using field notes for later analysis.

\section{Method of Analysis and Discussion}

As it has been already mentioned in research paradigm, data obtained from observation, and interview was analyzed qualitatively. The data obtained by classroom observation and through interview, which are in the form of words were organized and categorized according to their themes as they could be described and interpreted. 
The descriptions of classroom episodes were presented in narrative form by giving titles or forming hunches which were confirmed in the subsequent discussions.

\section{Analysis of Findings and Discussion}

The collected data were organized and analyzed in line to the objectives of the research. The data, both from classroom observation and interview were organized according to their themes which could be proved in the subsequent discussions.

\section{Analysis of Classroom Observation along with Awareness Issues: Analysis Procedures}

The observation schedule was planned for five purposefully selected teachers. The teachers themselves arranged the time/period and identify the topics for observation after discussion made with them on the purpose of the research. The length of one class time/ period observation was 40 minutes. The data of classroom observations were analyzed based on the series phases of constructivist approach, which are orientation, elicitation, intervention, review/reflection and application phases. Thus, the classroom episodes were analyzed vis-a-vis the constructivist strategy of teaching in science. To avoid redundancy of information/data, I preferred to omit the data that could make the discussion redundant. Accordingly, the classroom episodes of the observed teachers were portrayed, along with the interview data on teachers' awareness in the following discussions.

\section{I.Business as a Usual": Traditional, objectivist View of Teaching and Learning Science}

The classroom observation of all teachers revealed that, teachers' classroom episodes reflects objectivist views of teaching science. Throughout the entire classroom observation, as described below, the teachers were merely describing the scientific facts verbally.

In relation to this, the classroom observation (at 02:45, April 04, 2018) with Chala, who teaches grade 5 Integrated Science, narrated as follow,

The teacher started the instructional activities by revising the pervious lesson; by asking questions as "What did you learn in the previous lesson?" Then, some students were responded the questions by raising their hands. The teacher gave recognition for these who had answered the questions. After this, the teacher told the lesson topic of the day to the students and wrote the topics of the lesson on the black board, as: "The three ways in which heat transmitted: Conduction, Convection and Radiation."

Immediately, after he introduced the day's lesson, he ordered the students as "Be in group and identify difference between the three ways in which heat transmitted (Conduction, Convection and Radiation) using your textbooks," regardless of eliciting students' experiences. Then some students started reading their textbooks being in groups in response to teacher's questions. While others, were whispering with one another putting their books opened on the table and still others were sitting simply without books. Just after about 5 minutes the teacher took responses from a few students who raised their hands. Next to this, he told the students to follow his description of the topic attentively.

Then, Chala started description of scientific findings about the transmissions of heat via conduction, radiation and convection using text figures. Furthermore, Chala aided his verbal description of how heat transmitted via conduction with demonstration (using heat transmitting and non-heat transmitting materials). The students' learning experiences were limited to listening and watching to teachers' exposition; without engaging actively in the learning process. To this end, the teacher concluded his instruction by revising some points and inviting students to ask questions if any before he leaved the class.

When Chala's classroom observation was analyzed in relation to orientation and elicitation phases of constructivist approach, the classroom episodes did not reflects the constructive view of learning. Chala did not arouse students' curiosity into the lesson by providing learning contexts/practical learning materials that could inspire students to learn by doing in the process of learning. Instead, he was restricted merely to revising the previous lesson and introducing the day's topic verbally, without providing practical/familiar learning experiences as his starting point. As, intrinsic motivation and curiosity are stimulated by tasks that provide the opportunities of direct experience and personal control (Littledyke, 2001; NSRC, 1997).

Besides, Chala did not make attempts to elicit students' prior experiences or conceptions before letting students to read answers from their texts and getting into his descriptions. There were no opportunities for students to clarify their experiences and raise questions; rather than inviting students to answer questions from their textbooks. On the other hand, as Ausubel (1968,vi) quoted in Kumari and Sharma (2004:127) "the most important single factor influencing learning is what the learners already know. Ascertain this and teach them accordingly!"

Thus, Chala's classroom episodes did not show his understanding towards constructivist approach. Moreover, the empirical data obtained with interviews regarding his awareness, towards arousing students' curiosity and elicitation of learners' prior experiences revealed as follows,

It is important to arouse students' interests at the entry point of the teaching learning processes to make the students follow the instruction attentively. Regarding this, for example, I made the students to remember the previous topic by asking questions to 
stimulate their interest. Then, I introduced the day's lesson topics. Next, I make students to exchange their ideas in groups and present using their textbooks; before I described the details. For example, I arranged the students in groups and made them to discuss in groups about the difference between conduction, convection and radiation using their texts (Chala, April 11, 2018).

The above quotation revealed that, Chala did not have understanding of orientation and elicitation phases in a full sense. Because, his awareness towards arousing students' curiosity was merely confined to making the students to remember the previous lesson and introducing the day's topic. He did not state about provision of authentic/experiential learning materials or contexts that could focus students' thinking and encourage students to pose questions and search for answers based on their prior knowledge/experience (Littledyke, 2001; NSRC, 1997).

Besides, Chala conceptualized the elicitation phase as making students to restate the scientific facts from their textbooks. Rather than, assisting students to express their prior knowledge and thoughts from their experiences that could be tested in the subsequent activities. Conversely, child's existing knowledge and experience form the base for subsequent learning, which is not stated by Chala. Thus, science activities should begin with the teacher eliciting the pupils' existing ideas on the topic (Kumari and Sharma 2004; Mayer, 2003).

In addition, when Chala's classroom episodes was analyzed in relation to intervention and reflection/review phases of constructivist instruction, Chala's classroom episodes did not reflects the constructivist approach. As, evidences from classroom observations revealed, Chala did not provide learning opportunities that could enable students to practice and test to enhance their understanding of the concept. Hence, the students were deprived of opportunity to use their investigative skills to hone their understanding. Besides, the teacher did not provide opportunities for students to reflect on the process of learning and communicate what they have been achieved (Kumari and Sharma, 2004; Littledyke, 2001; NSRC, 1997). Thus the students' learning experiences were restricted to listening to teacher's expositions to acquire scientific findings passively.

When the underlying assumption of Chala's classroom episodes was examined, it did not reflect the constructivist conception of learning. Accordingly, Chala's awareness towards intervention and reflection phases illustrated as follows,

If students learn science practically, they become motivated and understand the topics in-depth.

For this, I taught them the conduction of heat with demonstration and the students were watching the events attentively. To the end, I invited them to ask questions if they have (April 11, 2018).

As, this quotation showed Chala conceptualized teaching and learning via demonstration, as it could achieve students' understanding. This conception of learning reflects the behaviorist/objectivist views of learning; the view that assumed knowledge could be conveyed directly through words or via information delivering methods and could be understood directly (Mayer, 2003; Littledyke, 2001; Hillocks, 1999). From this, one could conclude that Chala did not have awareness on constructivist view of learning. Hence, he did not raise opportunities that could enable students to learn by doing or testing their ideas to construct their own learning. Thus, the evidence both from classroom observation and interview revealed that, Chala's classroom episodes and understanding underline the objectivist/positivist view of teaching and learning.

Similarly, the classroom observation (at 01:50, April 04, 2018) with the second teacher, Desta, who teaches grade 6 Integrated Science, described as follows,

At the beginning of the class Desta used questions for students to remember the pervious lesson which was about refraction of light in different medium, reflection and reflectors of light. Next, the teacher introduced the day's lesson topic merely verbally, without providing hands-on materials/familiar experiences as: “Our today's lesson topics are about lenses and optical materials, such as, Microscope and Telescope as well as their importance. So, you need to follow attentively."

Then, Desta arranged students in groups and asked them questions to identify the optical materials and their importance before his presentations. Following this, the students started reading their textbooks for answers. Then after about 5 minute of time he told students to stop reading and discussion; and made students to give their responses from each groups; before his presentations.

Next, he started describing about the function of lenses by using one hand lens as an example. The teacher was showing how the lens could enlarge written words from the texts to a bigger size to each group by handling the lens himself. The students were motivated while looking at the lens at the hand of the teacher. In the meantime, I were expecting that he might give the lens to the students, at least to a group to enable them to handle it and see how it could enlarge objects. However, the teacher stepped into describing other topics, the number of lenses found in a microscope and telescope, as well as, their use; verbally from the textbook without providing models of these materials. Finally, before he leaved the class he asked the students to ask questions if they have.

When the introductory part of Desta's classroom episodes were analyzed vis-à-vis the orientation and elicitation phases of constructivist approach, the classroom episodes did not reflects the constructivist instruction. Desta did not provide contexts that could involve students inquisitively. As, the key feature of this phase is the provision of practical or familiar experiences, that enables students to make actual contact with materials or events. 
Besides, he did not inform students their active role in learning processes, which could arouse students' interest and curiosity (Kumari and Sharma, 2004; Littledyke, 2001; NSCR, 1997).

Thus, the classroom observation showed that, students' curiosity was boiled down to merely acquisition of teachers explanations. Besides, classroom activities provided by these teachers did not encourage students to give out what they think and know about the topic from their experiences/prior conceptions. This would actually help students to clarify what they already thought and knew and what they wanted to find more about. Littledyke (2001); NSCR (1997) suggested the aspects of this phase as: teachers' use of a variety of ways of finding out and probing students' ideas, and the valuing of students' expression of prior ideas as bases for the subsequent teaching and learning process. These aspects were not observed.

As, it could be understood form the narration of classroom episodes, Desta did not show understanding in relation to orientation and elicitation phases. In addition, the empirical evidence, data obtained via interview, concerning Desta's awareness towards arousing curiosity and elicitation revealed as follows,

At the first place it is important to arouse students' interests in teaching and learning processes. For example, in line to this, I made the students to remember the pervious lesson by asking questions as strategy. Then, I introduced the day's lesson topic. Next, I asked them to identify the importance of optical materials, such as; microscope, telescope and hand lenses using their books, in order to, participates them in learning processes; before I started the detail description of the lesson (April 13, 2018).

This quotation did not show Desta's deep understanding towards orientation and elicitation phases of constructivist approach. Because, Desta's awareness towards orientation was confined to revising the pervious lesson and merely introducing the day's lesson. Moreover, Desta's understanding of the elicitation phase reflected the objectivist/positivist view, merely making students to read and discuss the answer from their textbooks in groups. Unless the students are given opportunities to clarify their conceptions and feelings about the topic in their own way, using their own words an important means of gaining understanding is lost (Wells, 2002). Notwithstanding, in the interview data Desta, did not state strategies that could assists to draw out student's experiences/prior conceptions bout the topic, which could be proved in the subsequent activities. Rose (1998) suggested assessment activities in which prior ideas could be elicited as, asking the child: what do you know about this material? What can you make a good guess at? What would you like to know...?

In addition, when Desta's classroom observation was analyzed in relation to intervention and reflection/review phases of constructivist instruction, the classroom episodes did not show the constructivist view of learning. In the entire classroom observation Desta did not provided learning experiences that could enable students to "imagine with" and work out their ideas. As classroom observation, depicted that, there was no actual contact with the materials or events by students. Besides, Desta did not give opportunities for students to reflect on the process of learning and to communicate their understandings. Consequently, students' learning experiences were boiled down to listening to teachers' verbal description of the topic passively, rather than, being provided with learning materials that could enable them to learn constructively. In theses phases teachers ought to encourage children to test their ideas practically to support or verify with evidences and to communicate what they have found out (Littledyke, 2001; NSRC, 1997). If students allowed to test their ideas, they will develop: deep understanding of scientific concepts, investigative skills, and appropriate attitudes toward science (Kumari and Sharma, 2004; Byrne, 1997; NSRC, 1997).

On the other hand, Desta's classroom observation did not portray his understanding towards constructive view of teaching approaches. Moreover, regarding the intervention and reflection phases Desta's awareness portrayed as follows,

Involving students in practical activities have vital role in learning. For example, I still remember what my physics teacher showed us about electricity. Accordingly, I taught about lenses, by showing them hand lens as an example... But, hence, I couldn't find Microscope and Telescope I explain orally. Finally, I invite students to ask question if they have; before I leave the class (April 13, 2018).

As this quotation depicted, Desta's awareness of participating students in practical work was derived from retention of information via rote learning (Mayer, 2003), not from constructivist view of learning. That is, he conceptualized as knowledge could directly transfer from teacher to learner via expositions. He did not express his awareness about the importance of allowing students in making their own knowledge with the provision of practical learning materials. Moreover, Desta disguised his lack of commitment of providing learning materials (telescope and microscope or models) with lack of them (materials).

The empirical evidences both from classroom observation and interview revealed that Desta's view towards teaching reflected the traditional/positivist view of teaching. The view that held knowledge could directly transferred from the mind of teacher to the mind of learner (Hillocks, 1999; Mayer, 2003; Littledyke, 2001). This view not only neglects the students' constructive view of learning, but also, the central value of teaching sciencedeveloping skills of finding and communicating scientific facts/truths (Kumari and Sharma 2004; Garson, 2002:3; 
Byrne, 1997).

Likewise, the third classroom observation (at 03:25, April 05, 2018) held with Hateu, who teaches grade 6 Integrated Science and his classroom episodes were narrated as follows,

Hateu, began his class by revising the pervious lesson (human nervous system) for about 5 minute. Following this, he introduced the day's topics (refraction of light in different medium and reflection and reflectors of light). After that, he ordered the students as, "Form groups and discuss on the topic using your textbook." Following, the students started reading and sharing their ideas among the group on the topics. After a few time, the teacher told the students to stop discussion to give out their ideas from the text. Then, after he listend to students' responses he told the students, to pay attention to follow his explanation by saying "You need to pay attention carefully, hence I construct test out of it."

Then, he began giving description about refraction of light in different medium, reflection and reflector of light merely verbally using textbook, without providing any practical/experiential learning materials. The students' learning experiences were reduced to listening to the teacher's lectures and reciting it for tests as the teacher told them. To this end, the teacher revised the topic and invited the students to ask the questions if they have before he leaved the class

When the introductory part of Hateus' classroom episodes was seen in line to constructivist approach, the instructional activities did not show any attempts in stimulating students' curiosity and eliciting prior ideas. The teacher did not provide practical/experiential materials and did not make the students to clarify their prior ideas that could arouse students' curiosity, which are the components of orientation and elicitation phases (Littledyke, 2001; Black, 1999; NSRC, 1997), rather than confining them to restate scientific facts from their textbooks and listen to his verbal explanation attentively. Kumari and Sharma (2004) suggest a teacher who relies only on instruction, who forestalls expression of students' ideas and experiences instead of asking further questions to draw out students' ideas which will set them on the way to their own solution will disincline them to learn. Thus, Hateu's classroom episodes did not show his awareness towards constructivist instruction.

Moreover, the underlying assumption of Hateu's classroom episodes towards stimulating students' curiosity and elicitation was portrayed via interview as follows,

Arousing students' motivation towards teaching and learning processes is a key factor for students' learning, before presenting the day's lesson. For example, for this purpose I asked question to remember the pervious lesson then I introduced the day's topic. Besides, I tried to stimulate their interests towards lesson for example by saying just at the end of this instruction you will be asked questions and quizzed. Next, I made the students to discuss in groups on the topic using their texts before I made explanation (April 09, 2018).

This quotation portrayed that, Hateu understood the practices of awakening students' curiosity and elicitation of prior conceptions, as merely revising the pervious lesson and introducing the day's topic. Besides, he perceived giving test at the end of the lesson, as it could motivates the students towards the lesson. Hateu's understanding towards arousing motivation was derived from behaviorist approaches, which considered the basis of motivation as rewards and punishments (Mayer, 2003; Littledyke, 2001). On the other hand, the responsibility of primary school teachers is to build on and strengthen children's intrinsic motivation and curiosity in learning and lead them to learn for themselves rather than from fear of disapproval or desire for praise (Moyles, 2002; Wells, 2002; NSRC, 1997).

So, from this, one could conclude that Hateu did not have deep awareness on how to arouse student's motivation and draw out students' prior experiences. Hence, both in classroom observation and interview made with him (Hateu), he did not use and raise any markers that could arouse curiosity and draw out students' prior ideas/conceptions.

Moreover, when Hateu's classroom episodes were analyzed vis-a-vis intervention and reflection/review phases of constructivist approach, Hateu did not apply the intervention and reflection/review phases of constructivist instruction. Because, his classroom episodes did not show when he assist the students to test their prior ideas and to reflect the significance of what they have found out. Instead, he made the students to follow his subsequent instruction passively, without providing practical/ hands-on learning materials, which could enable them to be engaged actively in learning process by hypothesizing and working for confirmation (Kumari and Sharma, 2004; Littledyke, 2001; NSRC, 1997). Regarding this phase, classroom episodes should include activities such as: providing experiential/practical learning materials, encouraging students to work out and support their ideas with evidences and helping them to reflect on the process and the significance of what they have been achieved.

In addition, the empirical evidence from interview also showed that Hateu did not have awareness towards intervention and reflection phases of constructivist approach.

In the interview Hateu responded as follows,

We teach science practically in the laboratory. However, for this matter we don't have enough 
equipments and materials to teach science practically. Consequently, I use practical activities rarely (April 09, 2018).

As, this quotation revealed, Hateu did not have awareness towards constructive view of learning. Hence, he did not raise any markers of intervention and reflection phases, that is, how to assist students to test their ideas and communicate what they found out. Hence, a child brings ideas of his or her own to the classroom, and the aim of science education is then to adapt or modify these original ideas so as to give them more explanatory power (Kumari and Sharma, 2004).

Besides, he did not have the understanding, that practical activity is an integral part of science learning. Hence, he detached practical learning experiences/activities from classroom instructional practices to laboratory works. However, teaching and learning science practically would not only reserved to laboratory work of sometime, necessarily with sophisticated equipments; but also it should be understood as in integral part of science instructional activities by making use of locally available materials (Tobin, 1990).

Similarly, Gadise's, grade 1 environmental science teacher, classroom observation (at 09:20, April 03, 2018) narrated as follows,

Gadise started her classroom instruction as others did, by remembering her students the previous lesson. Then she introduced the day's lesson topic as "our today's lesson is about the effects of wind. So, you need to follow the instruction carefully." Next she ordered the students to see and share their ideas about the pictures that illustrate the different effects of wind from their textbooks. Accordingly, the students were talking to one another by looking at the pictures from their texts. After a while, the teacher asked the students as "as you looked at the pictures from your texts, who tell us the effects of wind?" Next the students responded as they had looked to the pictures from texts.

After this, the teacher made detail descriptions on the effects of winds and the events that show the presence of wind based on the texts. The students were listening to her description and taking notes from the chalkboard. In the meantime, "the subject of a day", the wind, was in action-blowing flags and trees outside the classroom while the students confined in the classroom and listen to teachers' lectures. Meanwhile, I was expecting as she could let the students to go out to observe and experience directly the events made by wind outside the classroom. Since, one of the most important responsibilities of teachers is to help children to see order and pattern in experience and to extend their ideas by analogies and by the provision of suitable vocabulary (Kumari and Sharma, 2004; Holt, 2002).

When Gadise's classroom episodes were analyzed from constructivist view of learning she did not enable students to organize and describe their prior experiences before letting the students to find answers from their textbooks.

Furthermore, Gadise did not allow the students to learn directly by experiencing and observing the phenomenon of wind; while the wind was blowing the trees and other thing outside the classroom. During classroom observation, her classroom episodes were merely confined to restating and writing the events that show the presence of wind on the blackboard from her texts; without using opportunities that could strengthen learning constructively.

Besides, the interview data, regarding her constructivist conception of learning as follows,

The need to participate students in learning process is unquestioned. For this, I arranged the students in groups and made them to identify the pictures which show events of wind from their textbooks and the students were participated by discussing with one another and by answering the questions. Then I make the lesson brief by giving them description (Gadise, April 10, 2018).

As this quotation showed, Gadese's view reflects the traditional/behaviorist approaches of learning, letting students to merely reading and restating the scientific facts from the book. The assumption that held knowledge could be conveyed directly through words or via information delivering methods/expositors and could be apprehended directly by anyone having adequate facility in the language (Mayer, 2003; Littledyke, 2001; Hillocks, 1999). Throughout the classroom observation and interview made with teachers, both the classroom episodes and interview data did not reflects the constructivist approach. To the constructivist knowledge cannot be transmitted. It has to be constructed afresh by each individual on the basis of what is already known and by exploring the events. II. Analysis of Attitude Issues

Teachers' attitude towards constructivist view of learning were analyzed in terms teachers' belief towards students' motivation and capability in constructing knowledge with learning materials presented to them in teaching learning process. These beliefs could be expressed by focusing on, listing students' strengths or weakness to construe their learning. In this study, the views that focused on students' potencies were taken as markers of optimistic attitude. Similarly, views that merely focused on students' deficiencies were analyzed as markers of pessimistic view in the analysis (Yalew, 2004; Littledyke, 2001; Hillock, 1999).

III.Mixed Feelings with More Pessimistic view

As interview data to the question, how teachers see students' motivation in constructing their own knowledge? 
Chala responded as:

The majority of students do not have interest in extracting their own knowledge. For example, while I gave them class activities to discuss in group using their textbooks, they did not pay attention to the activity. Instead they whisper and looking at one another across the groups. However, some, clever, students, participate actively (April 11, 2018).

As, this quotation revealed, Chala's view towards students' motivation was emerged from students' interest and attentiveness to his instruction. Regard less of, providing learning experiences that could arouse students' motivation to learn in line to constructivist approach. Even, I hesitate as this teacher acquainted with the commonly known VAK (Visual, Auditory and Keneastatic) learning styles. Because, different students stimulated in learning process with diversified leaning experiences. As, Holt (2002) stated, if the situation, the materials and problems before, a child do not interest him/her, his/her attention will slip off to what does interest him/her. Children are more stimulated by the teacher who is as curious about science as they are and who can find ways for them to explore their own inquires, than they are by the teacher who knows and tells all the answers (Kumari and Sharma, 2004; Lewis and Potter, 1970).

Similarly, Desta expressed his position as:

Some students, who are higher and average achievers, participate willingly in the classroom. However, many other students did not show interests while they are given with activities to discuss and present. Due to this, I prefer to teach them via direct instruction to make the knowledge accessible to all students (April 13, 2018).

Moreover, Hateu responded to the same question with more pessimistic view as:

Several students do not have interest in taking part in discussion to extract their own understanding. For instance, in the classroom when they are given with activities from their textbooks, they do not excited. They do not listen to one another. They consider group work as wasting time (April 09, 2018).

Accordingly, during his classroom observation he was telling the students to follow his instruction attentively, by warning them as they could have a test at the end as strategy. This was emerged from his thinking that students do not have interest and pay attention to their learning as the above quotation portrays. This assumption, made the teachers to belief as devising the opportunity for students to attempt to construct their own knowledge is to force them into relatively passive role, with a consequent reduction in their commitment to the endeavor of constructing meaningful knowledge (Moyles, 2002; Wells, 2002).

To the second questions, how the teachers view students' abilities towards constructing their own knowledge? Chala responded as: outstanding

A few, clever, students could construct their own understanding. But, others couldn't construct their own knowledge. Even, it is difficult to them to understand what I teach/give them, let alone to construct by themselves (April 11, 2018).

This stance of ability labeling was based on the ability of acquiring teachers' lectures. In spite of, providing learning opportunities that could enable students to learn in doing constructively. This thinking influenced the teachers to incline on frontal instruction in teaching learning process as classroom episodes revealed too.

Desta, responded in the similar way as: "Some students, who are higher and average achievers, could construct their own knowledge. But many other students, who are slow learners, could not make their own knowledge (April 13, 2018)."

Students will of course vary in the degree of interest that they show and their urge to learn will be strengthened or weakened by the attitude of the teacher. Children will act intelligently, when the teacher accepts and values their ideas and contributions as well as facilitates situations that engage them actively in all the process involved. Conversely, children can also learn to be passive from a teacher who allows them little scope in managing their own affairs and in learning (Kumari and Sharma, 2004; Holt, 2002; Wells, 2002).

Furthermore, Hateu responded to the same question with more pessimistic views as Many students could not make a worthwhile knowledge on their own. They do not have the experience of making their own knowledge. Even, they could not write words correctly. Hence, I prefer teaching via exposition (Apri 09, 2018).

Similarly, Gadise expressed her stances to the same question as:

They could not make their own knowledge. Because, they are not matured enough to construct their own learning. They did not acquire the skills of constructing knowledge. Hence, they need to be taught directly (April 10, 2018).

As the above quotations revealed, teachers underestimate the fact that the child is agent in his own learning and assumed the mind of the child as a vessel to be filled. Children can construct their own meaning and form concepts, so long as they work at their own level, and are not made to feel that they are failures (Mayer, 2003; Moyles, 2002; Wells, 2002). 
Therefore, above quotations showed that, teachers' made statements of non-optimistic attitude, towards students' motivation and abilities to learn on their own. They attributed the ability of constructing their own learning to a few students, "higher and average achiever," by disregarding the majority of students. This attitude of undermining students' interests and capacities towards constructivist view of learning could influence the teachers to rely on lectures and expositions as pivotal approach of instructional activities. The underpinning assumption of this attitude is the deep rooted thoughts of behaviorist view of teaching and learning and lack of awareness towards constructivist approach. This thinking made the teachers not to make students free to learn by doing, as well as, not to plan and provide diversified/multisensory learning materials/resources in line to the constructivist view of learning.

\section{Summary of the Finding, Conclusions and Recommendation Summary and conclusions of the Findings}

The study revealed teachers' practices, awareness and attitude towards the constructivist approach. In the entire classroom observation, teachers' classroom episodes did not reflect the constructivist approach. The teachers were using the traditional approaches, lectures as pivotal tools in their classroom episodes. Teachers did not provided learning opportunities that could: arouse students' curiosity and motivation, help students to clarify their prior conceptions or experiences, assists students to test their prior conception and reflect on the process of learning. The teachers' activities were confined to restating the scientific facts from the textbook, without providing learning context which could enable students to learn in line to constructivist approach. The students' learning experiences were boiled down to listening to teachers' lectures and repeating scientific findings of what they had been told or from their texts parrotely.

Teachers did not have awareness towards constructivist approaches in depth. In the entire interviews teachers did not raised markers of constructivist approaches in a full sense. In other words, teachers did not state the strategies how to: arouse students' curiosity and motivation, help students to describe their prior conceptions or experiences, assists students to test their prior conceptions and reflect on the process of learning. Their understanding confined to the statements of merely revising the previous lesson for arousing students' motivation and curiosity in the introductory part, and group discussion which is merely reading of scientific findings/answers from texts for eliciting students' ideas, and teachers' demonstration(if any) as practical learning. Rather than, stating methods of: awakening students' curiosity, eliciting learners' prior ideas, and methods of enabling students to modify their prior conception or strengthen their scientific understanding of the topics. Teachers perceived as their direct teaching of scientific findings via lectures and demonstration could develop the understanding of scientific concepts of their students. This thought reflects the positivist epistemology of knowing.

Teachers' attitude regarding students' motivation and capabilities in their learning towards constructivist view of learning depicted non-optimistic views. The teachers did not mention about of students' abilities as they could pursue in constructing their own knowledge in a full sense. Teachers' optimistic statements about students' motivation and abilities of learning on their own were restricted to "higher achievers" by undermining the majority of students with diversified ideas and capabilities in the classroom. Regarding this, teachers were listing about the students' deficiencies mostly, as markers of their ineffectuality to learn constructively. This pessimistic view of teachers, on students' ability to learn constructively is derived from the deep rooted thought of behaviorist/objectivist views, which consider the mind of the child as "tabula rasa."

\section{Recommendations}

The study proposes the following recommendations.

$>$ The Regional Education Office, Oromia Education Bureau (OEB) ought to provide workshops, short term trainings on:

$\checkmark$ The central values/objectives of science education in general and of primary science in particular; for in-service teachers.

$\checkmark$ Constructivist approach as referent thinking in science education.

$\checkmark$ Conception of "how students learn what they learn;" to change teachers' positivist/objectivist view to constructivist view and to develop teachers' attitude and belief toward constructivist view of learning.

$>$ The Zonal Education Office and the Town Administration Education Office ought to arrange experience sharing among teachers of different schools on content pedagogy in line to constructive view of learning.

$>$ The Schools' Administrators also need to arrange experience sharing among science teachers on content pedagogy in line to constructive view of learning.

$>$ Teachers educators ought to develop the understanding of the would be teachers towards constructivist approach. 


\section{References}

Amare Asgedom (2004). Debates in Research Paradigms: Refelection in Qualitative Research In Higher Educatioin. The Ethiopian Journal of Higher Education, 1(1):41-61

Ary, D. Cheser, L.J. and Razavieh, A. (2002). Introduction to Research in Education. $6^{\text {th }}$ ed. Austeralia: Wadsworth.

Black, P. (1999). Assessment, Learning Theories and Testing Systems. In Murphy, P. (Ed.). Learners, Learning, and Assessment. (Pp: 118-134). London: Paul Chapman

Brice, R. (2001). Design and Technology: Constructive Learning in Action. In Littledyke, M. and Huxford, L.(Eds).Teaching the primary Curriculum for constructive learning. (Pp: 82-106). London: David Fulton.

Byrne, D. (1997). Science One. In cross, A. and Peet, G. (Eds). Teaching Science in the Primary School. (Pp:106121). United Kingdom: Northcote House.

Cottrel, S. (2001). Teaching Study Skills and supporting learning. New York: PAGRAVE MACMIILAN

Denzin, K. N. and Lincoln, S.Y. (1994). Hand Book of Qualitative Research. London: SAGE Puplications Garson, Y. (2002). Science in the Primary School: London: Routledge.

Hillock, G. Jr. (1999). The Ways of Thinking: The Ways of Teaching. London: Teachers College Press

Holt, J.(2002). Learning to be 'stupid'? In Pallord, A. (ED.). Reading for reflective teaching.(Pp:217- 218). London: Continuum.

Kim, J. (2005). The Effects of a Constructivist Teaching Approach on Student Academic Achievement, Self Concept and Learning Strategies. Korea: Chungnam National University.

Kumar, R. (1996). Research Methodology. A Step-by-Sstep Guide for Neginners. London: SAGE publications

Kumari, V and Sharma, S.(2004).Teaching Science for elementary Schools. New Delhi: Anmol

Lewis, J. and Potter, I. (19970). Teaching Science in the Primary School. (2 ${ }^{\text {nd }}$ ed). New York: Prentice Hall.

Littledyke, M. (2001). Constructivist Idea about Learning. In Littledyke, M. and Huxford, L.(Eds). Teaching the primary Curriculum for constructive learning. (Pp:1-40). London: David Fulton.

Mayer, R. E. (2003). Theories of Learning and Their application to Technology. In O’Neil, H. Jr. and Perez, R. S. (Eds). Technology Application in Education: A learning View. (Pp: 127-157).

Moyles, J. (2002). Teaching to promote active learning. In Pallord, A. (ED.). Reading for reflective teaching.(Pp:259-261). London: Continuum.

McGuigan, L. and Schilling, M. (1997). Children Learning in Science. In Cross, A. and Peet, G. (Eds.). Teaching Science in the Primary School. (Pp: 24-35). United Kingdom:Northcote House.

National Science Resources Center (NSRC). (1997). Science for All Children. Washington, DC: National Academy Press.

Petty, G. (2004). Teaching Today (3rd ed). United Kingdom: Nelson Thornes.

Rose, J. and Billett, S. (1999). Securing Conceptual Development in Work Place. In Murphy, P. (Ed.). Learners, Learning, and Assessment. (Pp: 329-344). London: Paul Chapman

Ross, R. (1998). Science: Brenda Grapples with the Properties of a Mern. In Littledyke, M. and Huxford, L.(Eds).Teaching the primary Curriculum for constructive learning. (Pp: 68-81). London: David Fulton.

Solomon Areaya (2004). Qualitative Research. Beyond a Number Game. Institute of Educational Research (IER)Flambeau, 11(2).

Transitional Government of Ethiopia (TGE). (1994). National Education and Training Policy.Addis Ababa: EMPDA.

Tobin,K.G. (1990). Laboratory in Science Education: Foundation for the Twenty-First Centuary.Retrived on Sept. 2018, from gpq.iqm.uncqmp.br/gtexprim..

Wells, G. (2002). Conversation and the reinvention of knowledge. In Pallord, A. (ED.). Reading for reflective teaching.(Pp:235-237). London: Continuum.

Yalew Endawoke (2004). Teachers' Beliefs, Knowledge and practices of Learner-Centered Approach in Schools in Ethiopia. The Ethiopian Journal of Education, XXIV (2): 1745 